\title{
Predicting Walking-Induced Oxygen Desaturations in COPD Patients: A Statistical Model
}

\author{
Ernesto Crisafulli MD PhD, Andrea Iattoni MD, Elena Venturelli PT, Gherardo Siscaro MD, \\ Claudio Beneventi PT, Alfredo Cesario MD, and Enrico M Clini MD
}

\begin{abstract}
BACKGROUND: Oxygen desaturation during walking can have important consequence on prognosis of COPD patients. However, a standard 6-min walk test (6MWT), useful in detecting desaturation in COPD patients, can be difficult to execute in some settings of COPD management, as in the community healthcare service. We evaluated a new scoring system for the risk of oxygen desaturation during walking in COPD patients: the walking desaturation score. METHODS: We collected data from symptomatic COPD in-patients admitted for rehabilitation (derivation cohort) and out-patients referred to the local community health service (validation cohort). $\mathrm{S}_{\mathrm{pO}_{2}}$ was monitored during 6MWT, and the subjects were classified as walking desaturators or non-desaturators. By a regression analysis model we assigned a weighted score proportional to the measured percentage of explained variance for each variable. Risk estimates were computed as odds ratios. A receiver operating characteristic curve analysis and a Hosmer-Lemeshow goodness-of-fit test were then performed to measure discrimination and calibration of walking desaturation score. RESULTS: Baseline characteristics in the derivation cohort $(n=435,74 \%$ of whom were walking desaturators) and the validation cohort ( $n=238,37 \%$ of whom were walking desaturators) were different. Resting arterial oxygen saturation measured from an arterial blood sample, $\mathbf{P}_{\mathrm{aO}}$, and percent-of-predicted $\mathrm{FEV}_{1}$ were the variables that predicted walking desaturation. The proportion of walking desaturators (and odds ratio estimate) gradually increased according to walking desaturation score (range 0-6) and associated categories of desaturation risk (total walking desaturation score: low 0 or 1 , high $2-3$, very high $4-6$ ) (chi-square $P<.001$ ). There was considerable predictive discrimination (area under the curve $0.90,95 \%$ CI $0.86-0.93, P<.001$ ), and calibration (Hosmer-Lemeshow chi-square 1.31, $P=.86$ ) values have been shown. CONCLUSIONS: Walking desaturation score accurately predicts and classifies the risk of walking desaturation in COPD patients. ClinicalTrials.gov Number NCT01303913. Key words: 6-min walk test; COPD; oxygen desaturation; community healthcare; decision making; risk score. [Respir Care 2013;58(9):1495-1503. (C) 2013 Daedalus Enterprises]
\end{abstract}

\section{Introduction}

The increase of expiratory flow resistance and mismatch of lung ventilation to perfusion ratio are common pathophysiological features in patients with COPD, leading to oxygen desaturation during exercise or activities of daily living. ${ }^{1-4}$

The authors are affiliated with the Department of Medical and Surgical Sciences, University of Modena and Reggio Emilia, Modena, Italy, with the exception of Dr Cesario, who is affiliated with the Department of Thoracic Surgery, Catholic University of Rome, Rome, Italy. Dr Clini is also affiliated with the Department of Pulmonary Rehabilitation, Villa Pineta Hospital, Pavullo nel Frignano, Modena, Italy.
The standardized 6-min walk test (6MWT)..$^{5}$ provides several responses regarding the walking capacity of COPD patients, ${ }^{6,7}$ and is useful and sensitive to identify individuals specifically showing desaturation by pulseoximetry. ${ }^{8-11}$ This finding may inform prognosis, since

\footnotetext{
The authors have disclosed no conflicts of interest.
}

Correspondence: Ernesto Crisafulli MD PhD, Department of Medical and Surgical Sciences, University of Modena and Reggio Emilia, Via del Pozzo 71, Modena, Italy. E-mail: ecrisafulli@pneumonet.it.

DOI: $10.4187 /$ respcare.02321 
COPD patients with walking desaturation have a higher mortality rate than patients without. ${ }^{12,13}$

In daily clinical practice a standard 6MWT can be difficult to execute in non-specialist settings, such as in a general practitioner's office or a healthcare service with low 6MWT expertise. ${ }^{14-16} \mathrm{We}$ evaluated a new scoring system for the risk of oxygen desaturation during walking in COPD patients, in a pure COPD population, using the combination of variables in the 6MWT.

\section{Methods}

This was a single-center, prospective study, executed following the approval of our institutional review board (registered at http://clinicaltrials.gov, NCT01303913). Patients gave their written informed consent to participate in the study. There were no external funding sources. The study was performed in the Department of Pulmonary Rehabilitation, Villa Pineta Hospital, Pavullo nel Frignano, Modena, Italy.

\section{Subjects}

Figure 1 shows the recruitment flow diagram.

\section{Derivation Cohort}

Consecutive and symptomatic COPD patients $(n=435)$ admitted for a hospital-based pulmonary rehabilitation course at our institution were assessed and enrolled between January 2010 and June 2011. The study coordinator confirmed the diagnosis and severity of COPD according to the Global Initiative for Chronic Obstructive Lung Disease (GOLD) guidelines. ${ }^{17}$

The exclusion criteria were: recovering from exacerbation or with a change in medications over the previous 4 weeks; other underlying pulmonary disease (either obstructive or restrictive); chronic respiratory failure and resting hypoxemia $\left(\mathrm{P}_{\mathrm{aO}_{2}} \leq 60 \mathrm{~mm} \mathrm{Hg}\right.$ or arterial oxygen saturation measured from an arterial blood sample $\left[\mathrm{S}_{\mathrm{aO}_{2}}\right]$ $\leq 90 \%$ on room air in a sitting position), with associated chronic and clinically evident non-respiratory conditions (eg, chronic heart failure, morbid obesity, and peripheral and/or cerebrovascular disease); unable to perform the $6 \mathrm{MWT}$ due to major neuro-motor limitations.

\section{Validation Cohort}

A sample of COPD out-patients $(n=238)$, assessed and enrolled between January 2006 and December 2010, served as the validation cohort (see Fig. 1). These subjects were naïve about pulmonary rehabilitation and were referred to the local community health service. The inclusion and

\section{QUICK LOOK}

\section{Current knowledge}

Oxygen desaturation during walking can have important consequences for the prognosis of patients with COPD. The standard 6-min walk test is useful for detecting patients who desaturate while walking, but the test is not available in all care scenarios.

What this paper contributes to our knowledge

The walking desaturation score accurately predicted and classified the risk of walking desaturation in patients with COPD.

exclusion criteria were the same as for the derivation cohort.

\section{Demographic and Anthropometric Measurements}

We recorded demographic, anthropometric, and functional variables. Body mass index was calculated by dividing body weight by the squared height in meters $\left(\mathrm{kg} / \mathrm{m}^{2}\right) .{ }^{18}$ Comorbidities were assessed based on the reported anamnesis and/or clinically evident signs or symptoms and without any formal functional assessment. Charlson Comorbidity Index, ${ }^{19}$ a self-reported score, was computed and recorded, not adjusted for age or diagnosis of COPD.

Arterial blood samples were obtained from the radial artery to obtain resting $\mathrm{P}_{\mathrm{aO}}, \mathrm{S}_{\mathrm{aO}_{2}}$, and $\mathrm{P}_{\mathrm{aCO}}$ by means of an automated analyzer (850, Chiron Diagnostics, Medfield, Massachusetts).

$\mathrm{FEV}_{1}$ and $\mathrm{FVC}$ were measured with automated spirometer (Masterscope, Jaeger; Hoechberg, Germany), with predicted values according to the Quanjer equation..$^{20}$ We assessed both the BODE (body mass index, air-flow obstruction, dyspnea, exercise capacity $)^{21}$ index and the ADO (age, dyspnea, and air-flow obstruction) ${ }^{22}$ index, which are validated prognostic measures in COPD subjects.

\section{6-Min Walk Test and Correlated Variables}

The 6MWT was conducted according to the current recommendations ${ }^{5}$ and performed indoors, in a corridor $50 \mathrm{~m}$ long and $3 \mathrm{~m}$ wide, under quiet conditions. Standardized instructions were provided to the subjects by 2 trained physiotherapists unaware of the study purpose. A pre-test evaluation (at least $30 \mathrm{~min}$ ) was performed to 

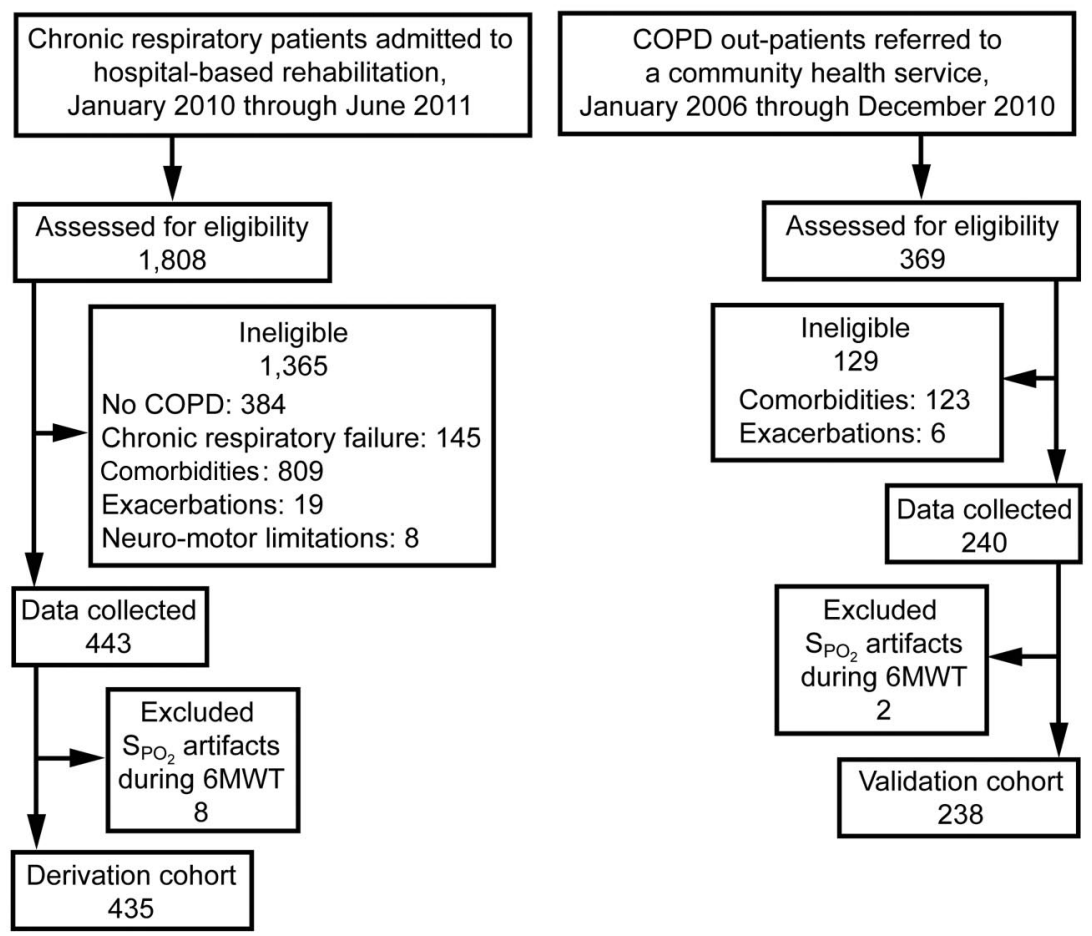

Fig. 1. Flow diagram. $6 \mathrm{MWT}=6$-min walk test.

minimize possible learning effect. ${ }^{23}$ The distance walked was recorded for analysis using the best of 2 consecutive tests.

$\mathrm{S}_{\mathrm{pO}_{2}}$ was continuously registered during the test, by a handheld and lightweight pulse oximeter (Pulsox 3, Minolta, Tokyo, Japan) with a finger clip. To minimize artifacts, the physiotherapist verified the signal quality and paid special attention when positioning the probe; every lost or fall in recorded signal was excluded from the analysis. The $\mathrm{S}_{\mathrm{pO}_{2}}$ nadir was then recorded.

An $\mathrm{S}_{\mathrm{pO}_{2}}$ fall of $\geq 4 \%$ and an $\mathrm{S}_{\mathrm{pO}_{2}}$ nadir of $\leq 89 \%$ during the $6 \mathrm{MWT}$ were considered as clinically important for walking desaturation during exercise and activities of daily living, ${ }^{24}$ and according to those parameters the subjects were categorized into desaturators and nondesaturators.

\section{Statistical Analysis}

Analysis was carried out with statistics software (SPSS 8.0, SPSS, Chicago, Illinois, and Analyze-it, Analyze-it Software, Leeds, United Kingdom). For all analysis, $P<.05$ was considered statistically significant.

We estimated the required sample size of the derivation cohort based on the consecutive referral of subjects to our center during a defined period (18 months). Since the minimal significant difference to observe a size effect was not known in the validation cohort, we established a priori that the percentage of subjects allocated to the derivation and validation cohorts should be $65 \%$ and $35 \%$ of the total, respectively. In the derivation cohort the data are expressed as median and $95 \% \mathrm{CI}$, mean $\pm \mathrm{SD}$, or number and percent. Comparisons between walking desaturators and non-desaturators were made by 2-way analysis of variance, chi-square, Fisher exact test, or Mann-Whitney U test, as appropriate. In a given cohort, bivariate correlation among all the considered variables and $\mathrm{S}_{\mathrm{pO}_{2}}$ nadir was estimated by Pearson correlation coefficient (r) or Spearman rho. Variables showing a strong relationship $(P<.01)$ were then entered into a multivariate stepwise regression test, with $\mathrm{S}_{\mathrm{pO}_{2}}$ nadir as the dependent variable.

To develop a prognostic score for walking desaturation (the walking desaturation score), we assigned to each variable significant in the regression analysis a weighted score that was proportional to each single percentage of explained variance $\left(\mathrm{R}^{2}\right) .{ }^{25}$ The cutoff level for allocating points was based on the percentile distribution within each variable. The populations were then divided into 3 categories (low, high, and very high risk), according to the associated risk score. The estimate of risk was computed as an odds ratio in a $2 \times 2$ table, as previously described by Rassi et al, ${ }^{26}$ with the formula:

Probability of walking desaturation $=\left(\mathrm{P}_{\mathrm{HR}}-\mathrm{P}_{\mathrm{LR}}\right) / 100$ 
Table 1. Descriptive Data of Subjects

\begin{tabular}{|c|c|c|}
\hline & $\begin{array}{c}\text { Derivation } \\
\text { Cohort } \\
n=435\end{array}$ & $\begin{array}{c}\text { Validation } \\
\text { Cohort } \\
n=238\end{array}$ \\
\hline Age, median (IQR) y & $72(56-84)$ & $72(53-82)$ \\
\hline Male/female, no. & $286 / 153$ & $176 / 62 *$ \\
\hline Body mass index, $\mathrm{kg} / \mathrm{m}^{2}$ & $26.5 \pm 5.2$ & $26.5 \pm 3.7$ \\
\hline $\begin{array}{l}\text { Charlson Comorbidity Index, } \\
\text { median }(\mathrm{IQR}) \dagger\end{array}$ & $1(1-2)$ & $1(1-2)$ \\
\hline \multicolumn{3}{|l|}{ GOLD stage, $\%$} \\
\hline I & 6.9 & $17.6+$ \\
\hline II & 48.0 & $59.7 \ddagger$ \\
\hline III & 36.6 & 21.0 末 \\
\hline IV & 8.5 & $1.7 \ddagger$ \\
\hline $\mathrm{FEV}_{1}, \mathrm{~L}$ & $1.13 \pm 0.44$ & $1.54 \pm 0.54 \ddagger$ \\
\hline $\mathrm{FEV}_{1}, \%$ predicted & $52.3 \pm 16.0$ & $63.9 \pm 16.8 \ddagger$ \\
\hline FVC, L & $1.89 \pm 0.72$ & $2.66 \pm 0.85 \ddagger$ \\
\hline FVC, $\%$ predicted & $80.0 \pm 20.6$ & $89.4 \pm 48.0 \ddagger$ \\
\hline $\mathrm{P}_{\mathrm{aO}_{2}}, \mathrm{~mm} \mathrm{Hg}$ & $68.9 \pm 7.3$ & $72.9 \pm 7.9 \ddagger$ \\
\hline $\mathrm{P}_{\mathrm{aCO}_{2}}, \mathrm{~mm} \mathrm{Hg}$ & $40.4 \pm 5.1$ & $39.3 \pm 4.2^{*}$ \\
\hline 6-min walk distance, $\mathrm{m}$ & $378.3 \pm 88.5$ & $415.9 \pm 76.7$ † \\
\hline $\begin{array}{l}\text { Arterial blood sample } \\
\quad \text { oxygen saturation, } \%\end{array}$ & $93.6 \pm 1.8$ & $94.8 \pm 1.6 \ddagger$ \\
\hline $\mathrm{S}_{\mathrm{pO}_{2}}$ nadir, $\%$ & $86.9 \pm 4.4$ & $90.1 \pm 4.0 \ddagger$ \\
\hline $\begin{array}{l}\text { MRC dyspnea score, } \\
\text { median (IQR) }\end{array}$ & $3(2-5)$ & $3(1-5)^{*}$ \\
\hline $\begin{array}{l}\text { Subjects with desaturation, } \\
\text { no. }(\%) \S\end{array}$ & $324(74)$ & $89(37) \ddagger$ \\
\hline \multicolumn{3}{|c|}{ 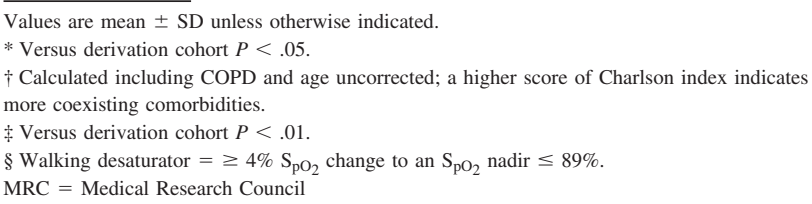 } \\
\hline
\end{tabular}

where $\mathrm{P}_{\mathrm{HR}}$ is the predicted probability at the higher risk, and $\mathrm{P}_{\mathrm{LR}}$ is the predicted probability at the lower risk in each category. ${ }^{27}$

Finally, the diagnostic discrimination and calibration properties of score (in the detection of walking desaturation event according described criteria) ${ }^{24}$ were measured by the area under the receiver operating characteristic curve $^{28}$ and with the Hosmer-Lemeshow goodness-of-fit test, respectively.

\section{Results}

Table 1 describes the study cohorts. Sixty-five percent of the derivation cohort were male, and $74 \%$ of them had walking-induced desaturation. Most of these subjects (85\%) had moderate to severe COPD (stages II and III, FEV 1 $52.3 \pm 16.0 \%$ of predicted), and their mean $\mathrm{P}_{\mathrm{aO}_{2}}$ was $69 \mathrm{~mm} \mathrm{Hg}$ at rest. In contrast, the validation cohort had less severe impairment in lung function $\left(\mathrm{FEV}_{1} 64 \%\right.$ of
Table 2. Bivariate Correlation Between COPD Characteristics and $\mathrm{S}_{\mathrm{pO}_{2}}$ Nadir in the Derivation Cohort

\begin{tabular}{lccc}
\hline \hline & $n$ & $\begin{array}{c}\text { Correlation } \\
\text { Coefficient* }\end{array}$ & $P$ \\
\hline Age & 435 & -0.01 & .86 \\
$\mathrm{Sex}$ & 435 & 0.01 & .96 \\
Body mass index & 435 & 0.09 & .17 \\
Charlson index & 435 & -0.07 & .24 \\
$\mathrm{FEV}_{1}, \mathrm{~L}$ & 431 & 0.31 & $<.001$ \\
$\mathrm{FEV}_{1}, \%$ predicted & 431 & 0.42 & $<.001$ \\
$\mathrm{FVC}, \mathrm{L}$ & 431 & 0.19 & $<.001$ \\
$\mathrm{FVC}, \%$ predicted & 431 & 0.26 & $<.001$ \\
$\mathrm{P}_{\mathrm{aO}}$ & 429 & 0.51 & $<.001$ \\
$\mathrm{P}_{\mathrm{aCO}}$ & 429 & -0.24 & $<.001$ \\
Arterial blood sample & 429 & 0.65 & $<.001$ \\
$\quad$ oxygen saturation & 435 & 0.12 & .02 \\
6-min walk distance & 435 & -0.15 & .001 \\
Dyspnea score & \multicolumn{3}{l}{} \\
& * Pearson or Spearman rho analyses were applied, depending on the type of variable. \\
&
\end{tabular}

predicted, $\mathrm{P}_{\mathrm{aO}_{2}} 73 \mathrm{~mm} \mathrm{Hg}$ ) and 6-min walk distance (416 $\mathrm{m}$ ), and a lower percentage of walking desaturators (37\%).

\section{Scoring System and Categories of Desaturation Risk}

In the derivation cohort the bivariate correlation (Table 2) and multivariate regression (Table 3 ) of the anthropometric and functional variables and $\mathrm{S}_{\mathrm{pO}_{2}}$ nadir as the dependent variable showed that resting $\mathrm{S}_{\mathrm{aO}_{2}}(r=0.65$ and $b=1.18), \mathrm{P}_{\mathrm{aO}_{2}}(r=0.50$ and $b=0.12)$, and percent-ofpredicted $\mathrm{FEV}_{1}(r=0.41$ and $b=0.08)$ significantly predicted walking desaturation.

After correlating each $\mathrm{R}^{2}$ of the significant variables in this cohort (Fig. 2), a total weighted score of $6(100 \%)$ was determined and specified as follows: $3 / 6$ points $(50 \%)$ for $\mathrm{S}_{\mathrm{aO}_{2}}, 2 / 6$ points (33\%) for $\mathrm{P}_{\mathrm{aO}}$, and $1 / 6$ points (17\%) for percent-of-predicted $\mathrm{FEV}_{1}$. The walking desaturation score range is $0-6$, as illustrated in Table 4 . A walking desaturation score of 0 or 1 indicates low risk, a score of 2 or 3 indicates high risk, and a score of 4-6 indicates very high risk for walking desaturation.

The distribution of COPD subjects according to walking desaturation score shows that walking desaturators gradually increase according to the score level: from $2 \%$ at a walking desaturation score of 1 , to $92 \%, 97 \%$, and $100 \%$ at walking desaturation scores of 4,5 , and 6 , respectively (chi-square $P<.001$ ), with a similar behavior regarding the categories of desaturation risk and odds ratio estimate (Fig. 3).

\section{Accuracy of the Walking Desaturation Score}

The accuracy analysis of the walking desaturation score in the validation cohort demonstrated considerable predic- 
Table 3. Multivariate Linear Stepwise Regression Analysis for Factors Predicting Walking Oxygen Desaturation in the Derivation Cohort*

\begin{tabular}{lcrr}
\hline \hline & $\begin{array}{c}\text { Unstandardized } \\
\text { Beta Coefficient } \dagger\end{array}$ & $95 \% \mathrm{CI}$ & $\begin{array}{c}\text { Standardized } \\
\text { Beta Coefficient }\end{array}$ \\
\hline Arterial blood sample oxygen saturation & 1.18 & $1.01-1.34$ & 0.50 \\
$\mathrm{P}_{\mathrm{aO}}$ & 0.12 & $0.07-0.16$ & 0.20 \\
$\mathrm{FEV}_{1}, \%$ predicted & 0.08 & $0.06-0.09$ & $<.001$ \\
Constant & -36.34 & -50.79 to -21.89 & $<.001$ \\
& & & \\
$*$ The dependent variable was $\mathrm{S}_{\mathrm{pO}_{2}}$ nadir. $\mathrm{R}^{2}=0.56 . \mathrm{R}^{2}$ change $=0.031$. & & \\
\hline
\end{tabular}

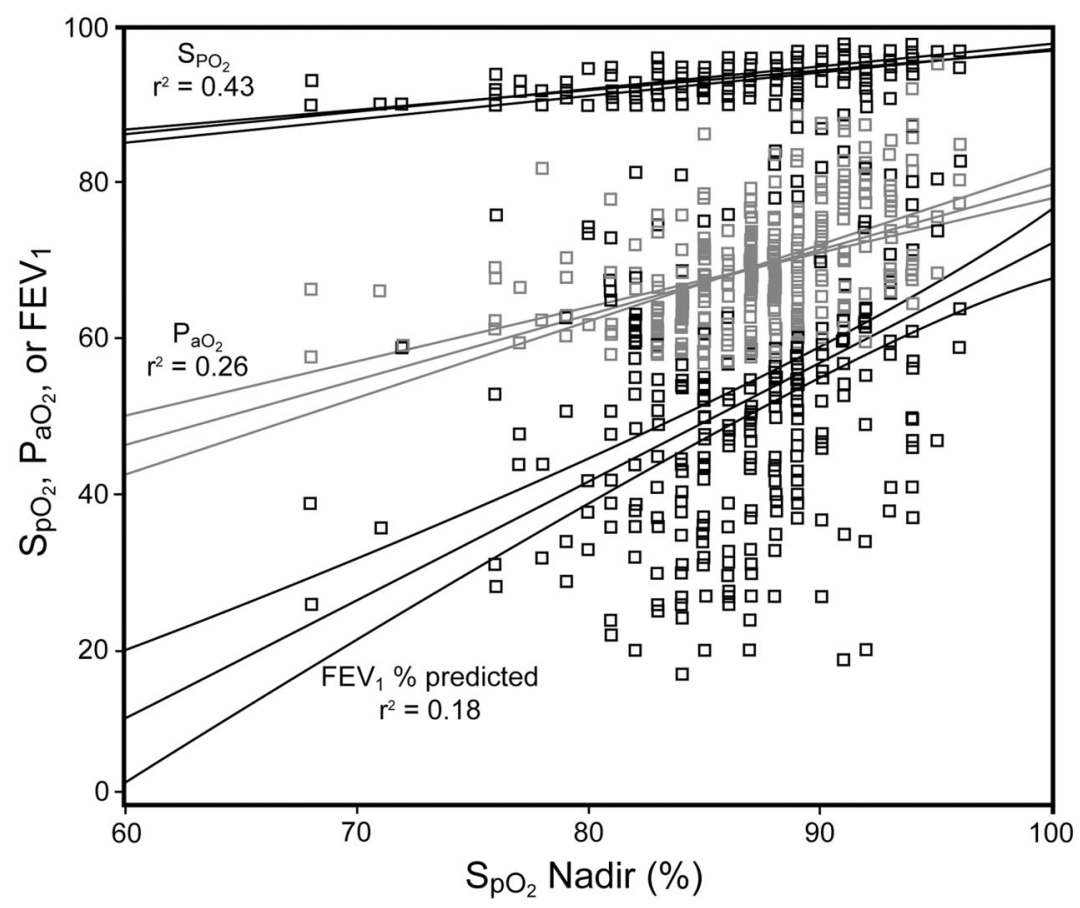

Fig. 2. Regression analysis of the derivation cohort. $\mathrm{R}^{2}=$ regression coefficient as a measure of explained variance.

tive discrimination (area under the curve $0.90,95 \%$ CI $0.86-0.93, P<.001, \mathrm{Z}$ statistic [measure of sensitivity] 22.57) (Fig. 4) and calibration (Hosmer-Lemeshow chisquare $1.31, P=.86)$ capacities.

\section{Correlation of the Walking Desaturation Score With Validated Prognostic Scores}

In the validation cohort the distribution of the BODE index scores (mean 1.85, 95\% CI 1.66-2.04) and the ADO index scores (mean 2.03, 95\% CI 1.79-2.27) shows a progressive increase according to the walking desaturation score and different categories of desaturation risk (Fig. 5). The correlation analysis indicates a significant relationship $(P<.001)$ between walking desaturation score and risk categories and the other prognostic indexes $(r=0.44$ and 0.23 for BODE, and $r=0.43$ and 0.22 for ADO, respectively).
Table 4. Walking Desaturation Scoring System

\begin{tabular}{lcccc}
\hline \hline & \multicolumn{4}{c}{ Walking Desaturation Score } \\
\cline { 2 - 5 } & 0 & 1 & 2 & 3 \\
\hline Arterial blood sample & $\geq 96$ & 95 & $94-93$ & $\leq 92$ \\
$\quad$ oxygen saturation, \% & & & & \\
$\mathrm{P}_{\mathrm{aO}}, \mathrm{mm} \mathrm{Hg}$ & $\geq 71$ & $66-70$ & $\leq 65$ & \\
$\mathrm{FEV}_{1}, \%$ predicted & $\geq 53$ & $<52$ & & \\
\hline
\end{tabular}

\section{Discussion}

The key message from our study is that a score (walking desaturation score) derived from variables easily and usually recorded in COPD patients can predict and classify the risk associated with walking-induced desaturation. Interestingly, the walking desaturation score and 3 categories of desaturation risk significantly correlated with other 


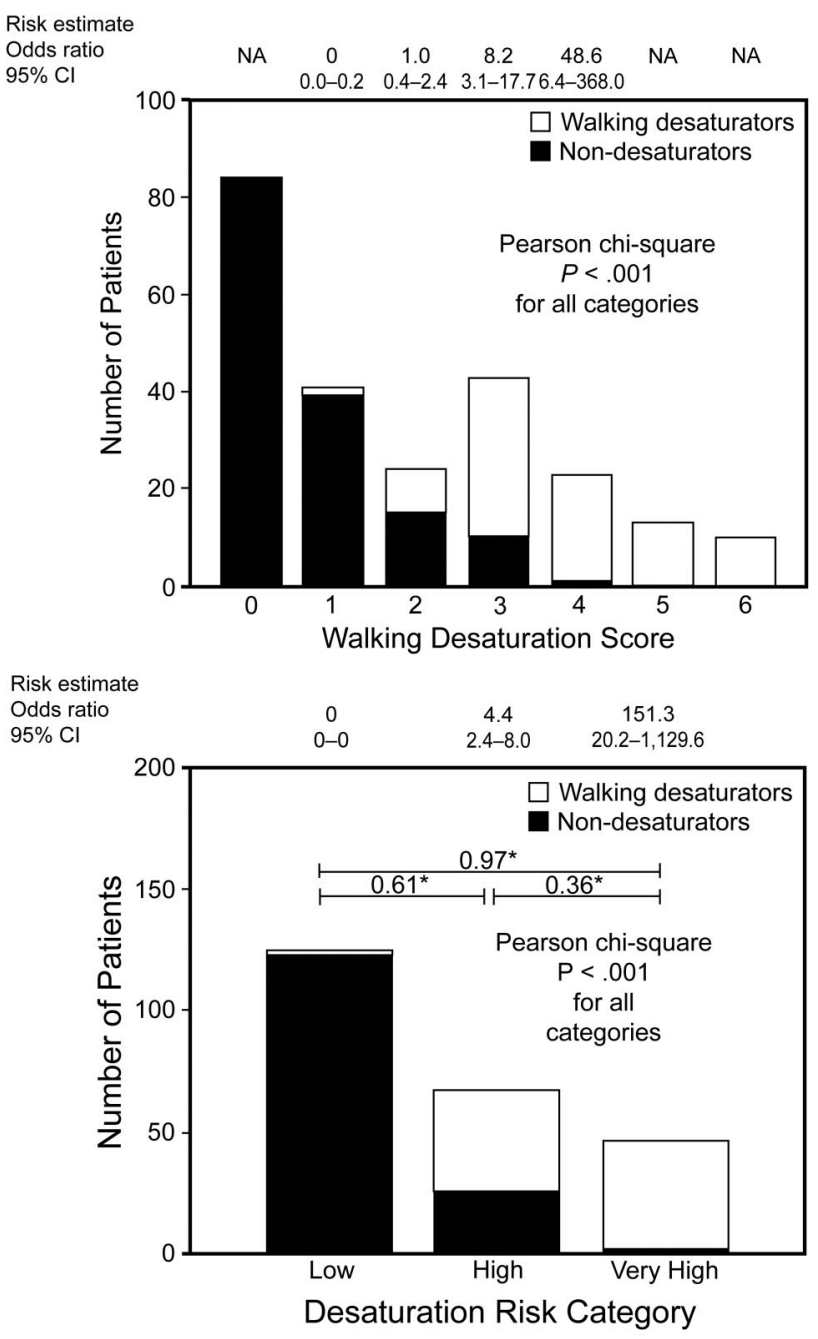

Fig. 3. Distribution of risk estimate in walking desaturators versus non-desaturators (see text). NA = not applicable because risk estimate cannot be computed for empty cells in a $2 \times 2$ table. * Difference in the probability of walking desaturation between the risk categories, calculated by the formula $\left(P_{H R}-P_{L R}\right) / 100$ (see text).

validated prognostic indexes (BODE and ADO) in this population.

Our findings suggest new and possibly clinically relevant information on how the degree of oxygen desaturation during usual daily physical activities may affect prognosis in pure COPD patients, by directly linking the likelihood of desaturation during physical exercise with a workable indicator of risk. ${ }^{12,13}$

Walking is the most common activity in daily life in COPD patients, ${ }^{7}$ so to indirectly evaluate the prognostic value of the walking desaturation score we considered its relation to other multidimensional grading scores, including assessment of walking ability (but not oxygen desaturation), ${ }^{21,22}$ that predict the risk of death from any cause.

The high discrimination and calibration power of the walking desaturation score (see Fig. 4) demonstrates its

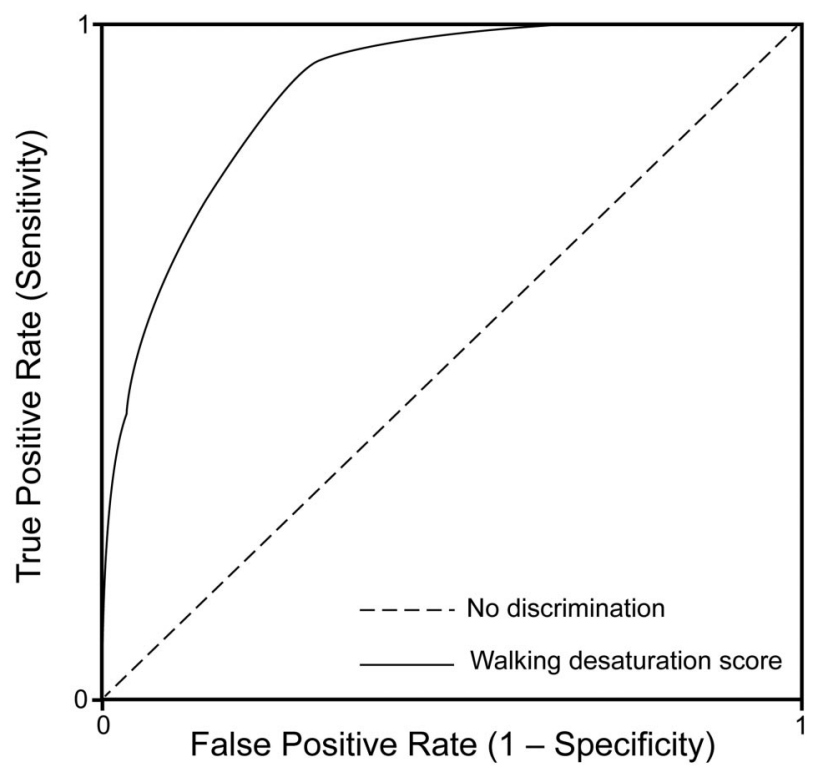

Fig. 4. Receiver operating characteristic curve for the validation cohort.

ability to identify walking desaturators among COPD patients. A higher walking desaturation score (4-6) almost certainly predicts walking desaturation; in contrast, a walking desaturation score of 0 or predicts a very low likelihood of desaturation (difference in probability 0.97) (see Fig. 3). In addition to this, a high risk difference in probability (0.61) was seen between the first (low) and the mid (high) risk class categories: this was the main reason we decided to name the middle category "high risk" rather than moderate risk.

From a clinical point of view, the easy application of the walking desaturation score may be of special interest for managing COPD patients at every level of care, including care outside the hospital. ${ }^{14-16}$ Indeed, in a "very first approach to COPD patients," the early screening of subjects at high and very high desaturation risk may assist physicians in diagnosis and testing and therapy selection, such as additional laboratory tests and/or ambulatory oxygen (although still questioned). ${ }^{24}$

Previous studies have demonstrated that forced volumes, ${ }^{29}$ diffusing capacity of the lung for carbon monoxide $\left(\mathrm{D}_{\mathrm{LCO}}\right)$, ${ }^{30-32}$ and resting $\mathrm{S}_{\mathrm{aO}_{2}}{ }^{29,33}$ predict exercise desaturation during 6MWT. In some of these, an $\mathrm{S}_{\mathrm{pO}_{2}}$ drop of $2-4 \%$ from baseline was used as the diagnostic criterion ${ }^{30,31}$; nevertheless, an $\mathrm{S}_{\mathrm{pO}_{2}}$ fall of $4 \%$ to $\leq 89 \%$ more strictly defines exercise desaturators and enables physicians to consider ambulatory oxygen therapy ${ }^{24}$ in patients with chronic lung disease. However, in none of those studies was introduced the method of multiple correlation and integration among variables, which were only defined as single predictors of that phenomenon. Statistically, to confirm the importance of this aspect, the predictive dis- 

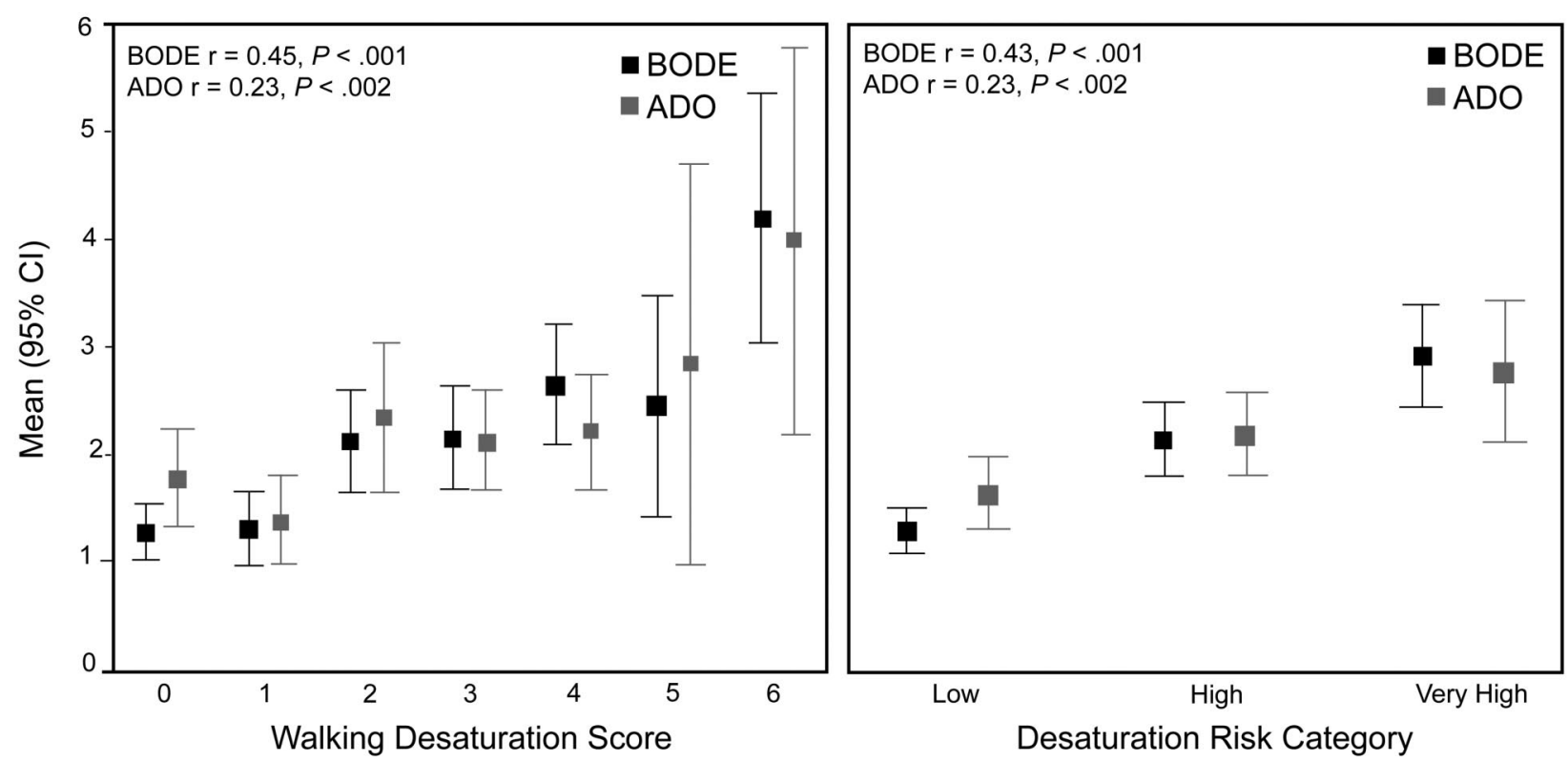

Fig. 5. Mean distribution of BODE (body mass index, air-flow obstruction, dyspnea, exercise capacity) index and ADO (body mass index, air-flow obstruction, dyspnea, exercise capacity) index scores versus walking desaturation score and desaturation risk category. The whisker bars represent the $95 \%$ Cls. The $P$ values are for mean comparisons between the groups.

crimination power of our walking desaturation score (measured by the area under the receiver operating characteristic curve) was very high (area under the curve 0.90, $P<.001)$.

With regard to the exercise-induced desaturation tests, previous studies ${ }^{30,32}$ did not refer to validated and 6MWTcorrelated tests (eg, 3-min step-test ${ }^{32}$ ) for assessing desaturation, nor did they indicate any clear criteria. In recent years, the 6MWT has been used more widely in clinical practice, and has shown to be the most sensitive test for exercise-induced desaturation ${ }^{8-11}$ and short-term response to supplemental oxygen. ${ }^{24}$ Furthermore, and in contrast with other non-walking exercise tests, the 6MWT reproduces more typical efforts in daily life, ${ }^{34}$ and this aspect has an excellent relationship with the ability of COPD patients to perform daily activities. From this point of view, the ability of our walking desaturation score to predict desaturation by 6MWT adds new information that may help in the daily management of patients with COPD.

In our study, the baseline characteristics were different between the 2 cohorts, stratified by temporal and spatial technique $^{28}$ (see Table 1). We think that this was because the patients came from different scenarios; for example, the network of ambulatories in the community care system is clearly a setting where less severe and disabled patients are normally observed and treated. A potential benefit of the baseline differences between the 2 cohorts is that it extends the validation data to a wider set of COPD stages, facilitating the process of recording relatively easy-to-catch variables that are directly able to predict the patient's complexity. Especially in these patients, the opportunity to accurately identify walking desaturators can eventually lead to important prognostic consequences and clinical decisions in long-term management.

Our study has 2 limitations to consider. First, our identification of comorbidities (likely present in COPD patients and causing oxygen perturbations) was exclusively based on patient self-report (Charlson Comorbidity Index) and clinically evident disease, so we excluded a priori all COPD patients with associated diseases (median unadjusted Charlson index score of 1). Thus we cannot exclude the possibility that COPD subjects with associated comorbidities at a subclinical level might have a theoretically biased set of results. However, we were not able to specifically assess any of the comorbidities usually present in COPD patients in our clinical setting. In any case, this could have led to underestimation of the true prevalence of the comorbidities.

Second, $\mathrm{D}_{\mathrm{LCO}}$ measurement was not planned for assessment in our study population. Two previous studies, ${ }^{30,32}$ in an unselected population, included different chronic lung diseases, and found that $\mathrm{D}_{\mathrm{LCO}}$ predicted oxygen desaturation during exercise. Even if $\mathrm{D}_{\mathrm{LCO}}$ has an important role in interstitial lung diseases, ${ }^{35}$ we cannot exclude the possibility that COPD with an emphysema phenotype might have a reduced $\mathrm{D}_{\mathrm{LCO}}$. Another study ${ }^{31}$ of $\mathrm{D}_{\mathrm{LCO}}$ to identify desaturators among COPD patients was, unfortunately, conducted with only 48 subjects and did not consider the standard walking test to properly assess exercise desaturation. Future studies are needed to answer this question. 


\section{Predicting Walking-Induced Oxygen Desaturations in COPD Patients}

\section{Conclusions}

Our study reports an original attempt aimed at identifying statistically derived stratifiers to model the risk of desaturation during 6MWT in a pure COPD population by a simple walking desaturation score. To our knowledge, this information has never before been elaborated, and could be useful in COPD management at the community level, outside any specialist setting. Finally, this approach might be useful and easy in rapidly obtaining information for clinical decision making in these patients.

\section{REFERENCES}

1. Robinson CW, White DP, Zwillich CW. Relationship of respiratory drives to dyspnea and exercise performance in chronic obstructive pulmonary disease. Am Rev Respir Dis 1987;136(5): 1084-1090.

2. van Meerhaeghe A, Sergysels R. Control of breathing during exercise in patients with chronic airflow limitation with and without hypercapnia. Chest 1983;84(5):565-570.

3. Soguel Schenkel N, Burdet L, de Muralt B, Fitting JW. Oxygen saturation during daily activities in chronic obstructive pulmonary disease. Eur Respir J 1996;9(12):2584-2589.

4. Palange P, Forte S, Onorati P, Manfredi F, Serra P, Carlone S. Ventilatory and metabolic adaptations to walking and cycling in patients with COPD. J Appl Physiol 2000;88(5):1715-1720.

5. American Thoracic Society. Guidelines for the six-minute walk test. Am J Respir Crit Care Med 2002;166(1):111-117.

6. Troosters T, Vilaro J, Rabinovich R, Casas A, Barberà JA, Rodriguez-Roisin R, Roca J. Physiological responses to the 6-min walk test in patients with chronic obstructive pulmonary disease. Eur Respir J 2002;20(3):564-569.

7. Clini EM, Crisafulli E. Exercise capacity as a pulmonary rehabilitation outcome. Respiration 2009;77(2):121-128.

8. Spence DP, Hay JG, Carter J, Pearson MG, Calverley PM. Oxygen desaturation and breathlessness during corridor walking in chronic obstructive pulmonary disease: effect of oxitropium bromide. Tho$\operatorname{rax} 1993 ; 48(11): 1145-1150$.

9. Turner SE, Eastwood PR, Cečins NM, Hillman DR, Jenkins SC. Physiologic responses to incremental and self paced exercise in COPD. A comparison of three tests. Chest 2004;126(3):766-773.

10. Poualin M, Durand F, Palomba B, Ceugniet F, Desplan J, Varray A, Préfaut C. Six-minute walk testing is more sensitive than maximal incremental cycle testing for detecting oxygen desaturation in patients with COPD. Chest 2003;123(5):1401-1407.

11. Escourrou PJL, Delaperche MF, Visseaux A. Reliability of pulse oximetry during exercise in pulmonary patients. Chest 1990;97(3): 635-638.

12. Takigawa N, Tada A, Soda R, Date H, Yamashita M, Endo S, et al. Distance and oxygen desaturation in 6-min walk test predict prognosis in COPD patients. Respir Med 2007;101(3):561-567.

13. Casanova C, Cote C, Marin JM, Pinto-Plata V, de Torres JP, Aguirre-Jaíme A et al. Distance and oxygen desaturation during the 6-min walk test as predictors of long-term mortality in patients with COPD. Chest 2008;134(4):746-752.
14. National Clinical Guideline Centre. Chronic obstructive pulmonary disease: management of chronic obstructive pulmonary disease in adults in primary and secondary care, 2010. http://www.ncgc.ac.uk/ Guidelines/Published/20. Accessed June 21, 2013.

15. Jones R, Gruffydd-Jones K, Pinnock H, Peffers SJ, Lawrence J, Scullion $\mathrm{J}$ et al. Summary of the consultation on a strategy for services for chronic obstructive pulmonary disease (COPD) in England. Prim Care Respir J 2010;19(Suppl 2):S1-S17.

16. Kocks JW, Asijee GM, Tsiligianni IG, Kerstjens HA, van der Molen T. Functional status measurement in COPD: a review of available methods and their feasibility in primary care. Prim Care Respir J 2011;20(3):269-275.

17. Global Initiative for Chronic Obstructive Pulmonary Disease (GOLD). Global strategy for the diagnosis, management and prevention of chronic obstructive pulmonary disease. http://www.goldcopd.org/guidelinesglobal-strategy-for-diagnosis-management.html. Accessed June 21, 2013.

18. Lohman TG, Roche AF, Martorell R. Anthropometric standardization reference manual. Champaign, IL: Human Kinetics; 1988.

19. Charlson ME, Pompei P, Ales KL, MacKenzie CR. A new method of classifying prognostic comorbidity in longitudinal studies: development and validation. J Chronic Dis 1987;40(5):373-383.

20. Quanjer PH, Tammeling GJ, Cotes JE. Lung volumes and forced ventilatory flows: report Working Party Standardization of Lung Function Tests, European Community for Steel and Coal; official statement of the European Respiratory Society Eur Respir J 1993; 16(Suppl):5-40.

21. Celli BR, Cote CG, Marin JM, Casanova C, Montes de Oca M, Mendez RA et al. The body-mass index, airflow obstruction, dyspnea, and exercise capacity index in chronic obstructive pulmonary disease. N Engl J Med 2004;350(10):1005-1012.

22. Puhan MA, Garcia-Aymerich J, Frey M, ter Riet G, Antó JM, Agustí AG et al. Expansion of the prognostic assessment of patients with chronic obstructive pulmonary disease: the updated BODE index and the ADO index. Lancet 2009;374(9691):704-711.

23. Knox AJ, Morrison JF, Muers MF. Reproducibility of walking test results in chronic obstructive airways disease. Thorax 1988;43(5): 388-392.

24. British Thoracic Society Working Group on Home Oxygen Services. Clinical component for the home oxygen service in England and Wales, January 2006. http://www.brit-thoracic.org.uk/Portals/ 0/Clinical\%20Information/Home\%20Oxygen\%20Service/clinical\%20 adultoxygenjan06.pdf. Accessed June 21, 2013.

25. Jones RC, Donaldson GC, Chavannes NH, Kida K, DicksonSpillmann M, Harding S, et al. Derivation and validation of a composite index of severity in chronic obstructive pulmonary disease. The DOSE Index. Am J Respir Crit Care Med 2009;180(12):11891195.

26. Rassi A Jr, Rassi A, Little WC, Xavier SS, Rassi SG, Rassi AG, et al. Development and validation of a risk score for predicting death in Chagas' heart disease. N Engl J Med 2006;355(8):799-808.

27. Harrell FE Jr, Lee KL, Mark DB. Multivariable prognostic models: issues in developing models, evaluating assumptions and adequacy, and measuring and reducing errors. Stat Med 1996;15(4): 361-387.

28. Altman DG, Royston P. What do we mean by validating a prognostic model? Stat Med 2000;19(4):453-473.

29. Jenkins S, Cečins N. Six-minute walk test: observed adverse events and oxygen desaturation in a large cohort of patients with chronic lung disease. Intern Med J 2011;41(5):416-422.

30. Kelley MA, Panettieri RA, Krupinski AV. Resting single-breath diffusing capacity as a screening test for exercise-induced hypoxemia. Am J Med 1986;80(5):807-812. 


\section{Predicting Walking-Induced Oxygen Desaturations in COPD Patients}

31. Owens GR, Rogers RM, Pennock BE, Levin D. The diffusing capacity as a predictor of arterial oxygen desaturation during exercise in patients with chronic obstructive pulmonary disease. N Engl J Med 1984;310(19):1218-1221.

32. Hadeli KO, Siegel EM, Sherrill DL, Beck KC, Enright PL. Predictors of oxygen desaturation during submaximal exercise in 8,000 patients. Chest 2001;120(1):88-92.

33. Knower MT, Dunagan DP, Adair NE, Chin R Jr. Baseline oxygen saturation predicts exercise desaturation below prescription thresh- old in patients with chronic obstructive pulmonary disease. Arch Intern Med 2001;161(5):732-736.

34. Palange P, Ward SA, Carlsen KH, Casaburi R, Gallagher CG, Gosselink R; on behalf of ERS Task Force. Recommendations on the use of exercise testing in clinical practice. Eur Respir J 2007;29(1): 185-209.

35. King TE Jr. clinical advances in the diagnosis and therapy of the interstitial lung diseases. Am J Respir Crit Care Med 2005;172(3): 268-279. 